\title{
Localization of international standards
}

\author{
Hiroshi Kadotani ${ }^{1}[1]$
}

Published online: 13 June 2020

(c) Japanese Society of Sleep Research 2020

It is important to use international guidelines and classifications to compare prevalence and clinical symptoms internationally. However, it is sometimes essential to use local definitions and diagnostic thresholds to fit with health policy of the nation.

For classification of diseases, ICD-10 (International Statistical Classification of Diseases and Related Health Problems 10th Revision) has been used for classification and statistical analysis of diseases worldwide [1]. Localization of the ICD-10 was developed in Canada (ICD-10-CA) [2] and Australia (ICD-10-AM) [3]. In Canada, more detailed data pertinent to morbidity were needed. In Australia, more specificity might be required. These are why national modifications of ICD-10 were developed in these countries. However, developing and maintaining a national modification is very resource intensive. In the new version of ICD (ICD-11), most of the modifications were included [4].

For diagnosis of sleep disorders with polysomnography and home sleep apnea testing, the American Academy of Sleep Medicine Manual for Scoring of Sleep and Related Events (AASM Manual) is widely used in the globe [5]. The AASM Manual had some alternatives, disparities and priorities with little or no relevance to Australasian patient management practices. Thus, the first commentary on the AASM Manual by Australasian Sleep Association (ASA) and Australasian Sleep Technologists Association (ASTA) was developed in 2010 [6]. To update the commentary to match the current AASM manual and to better fit with the Australian medical practice, new commentary was developed and published in the Sleep and Biological Rhythms [7]. Recommendations provided in the new commentary will improve standardization across Australasian sleep services and may contribute to the future updates of the AASM Manual.

Hiroshi Kadotani

kadotani@belle.shiga-med.ac.jp

1 Department of Sleep and Behavioral Sciences, University of Medical Science, Otsu, Shigu, Japan

\section{References}

1. World Health Organization. International statistical classification of diseases and related health problems. 10th revision, edition 2010. 3 v. Geneva: The World Health Organization; 2011.

2. Canadian Institute for Health Information. International Statistical Classification of Diseases and related health problems, tenth revision, Canada (ICD-10-CA). Geneva: The World Health Organization; 2018.

3. Australian Consortium for Classification Development. International Statistical Classification of Diseases and Related Health problems, tenth revision, Australian modification (ICD-10-AM). Lidcommbe: Australian Consortium for Classification Development; 2019.

4. World Health Organization (2020) International Classification of Diseases 11th Revision. The World Health Organization, Geneva, Switzerland. 2019. https://icd.who.int/en. Accessed 5 Jun 2020.

5. Berry RB, Quan SF, Abreu AR, Bibbs ML, DelRosso L, Harding SM, et al. (2020) The AASM manual for the scoring of sleep and associated events: rules, terminology and technical specifications, version 2.6. Darien, Illinois: American Academy of Sleep Medicine; 2020. https://www.aasmnet.org/scoringmanual/. Accessed 5 Jun 2020.

6. Thornton AT, Ruehland WR, Duce B, Wheatley JR, Douglas J, Rochford PD, et al. (2010) ASTA/ASA Commentary on AASM Manual for the Scoring of Sleep and Associated Events. https:// sleep.org.au/Public/Resource-Centre/F-Sleep-docs/ASTA-ASAcomm.aspx. Accessed 5 Jun 2020.

7. Jorgensen G, Downey C, Goldin J, Melehan K, Rochford P, Ruehland W. An Australasian Commentary on the AASM manual for the scoring of sleep and associated events. Sleep Biol Rhythm. 2020. https://doi.org/10.1007/s41105-020-00259-9.

Publisher's Note Springer Nature remains neutral with regard to jurisdictional claims in published maps and institutional affiliations. 